\title{
Economic Burden of Infectious Diseases and Benefit of Control and Prevention in Sub-Saharan Africa
}

\author{
Verner N. Orish \\ Department of Microbiology, School of Medicine, University of Health and Allied Sciences, Ho, Ghana \\ Email: Orishv@yahoo.com
}

Received 20 November 2015; accepted 4 December 2015; published 10 December 2015

Copyright (C) 2015 by author and OALib.

This work is licensed under the Creative Commons Attribution International License (CC BY). http://creativecommons.org/licenses/by/4.0/

(c) (i) Open Access

\begin{abstract}
Infectious disease is a serious global health problem. However, its negative impact is felt more in sub Saharan Africa. Epidemiological figures have shown that the burden of infectious disease is highest in the African continent especially in sub Saharan Africa. A majority of people leaving in sub Saharan Africa are poor and their exposure to infectious disease worsens their poverty situation. Aside impoverishing infected individuals, infectious diseases also directly negatively impact the economy of the country involved, reducing economic growth and productivity. Diseases like malaria, HIV, tuberculosis TB, and other epidemic prone diseases like Cholera and Ebola constantly pose a threat to economic development in Sub Saharan Africa. It is therefore pertinent to invest in disease prevention strategies to curb the burden and reduce the impact of infectious diseases on the economy of countries in sub Saharan Africa. This mini review re-echoes the burden of infectious diseases and discusses ways and strategies to reduce the burden of these diseases and the economic benefits that will be accrued at the long run.
\end{abstract}

Keywords

Infectious Diseases, Malaria, Economic Burden, TB, HIV Control Programmes

Subject Areas: Infectious Diseases

\section{Introduction}

Infectious diseases constitute a serious global health problem. The global threat of infectious diseases has never been higher any time in history of mankind than this present generation. Human migration, global trade, technological advancement in air travels, rapidly mutating disease causing microorganism, have predisposed the 
world to fast spread of infectious diseases [1]. The negative impacts of infectious diseases have been felt all over the world especially in developing nations like countries in Sub-Saharan Africa.

Epidemiological and clinical data clearly show that the burden of infectious diseases is more in Sub-Saharan Africa, with infectious disease consisting a large percentage of disease load in Sub-Saharan Africa [2] [3]. Despite progress being made globally in reducing the morbidity and mortality of infectious disease, sub Saharan Africa is sadly and painfully lagging behind [4]. Infectious diseases constitute about $70 \%$ of burden of disease leading directly and indirectly to most childhood and maternal deaths [5] [6]. Favorable climate and geographical suitability of many of the disease causing agents and its vectors are the culprits of the persistent and perennial presence of these infectious diseases [7]. Of course, poverty, illiteracy, poor sanitation, political instability, conflicts, wars, famine and poor health infrastructure are other persistent features prevalent in Sub-Saharan Africa that initiate and worsen the spread of infectious diseases [6]. The majority of these infectious disease seen are usually among the endemic "big three" malaria tuberculosis TB and HIV/AIDS with contributions from epidemic diseases like cholera, Ebola and other emerging infectious diseases. Malaria, HIV/AIDS and TB accounted for about $10 \%$ of all death in middle and low-income countries [8]

There is insufficient fund to finance health care in Sub-Saharan Africa. In 2009, it was estimated that countries in this region used approximately of $6.1 \%$ of its GDP on health far less that the $9.5 \%$ used by high income countries. This translates to about 25 dollars per person in Sub-Saharan Africa compared to 4600 dollars per person for high income countries [9]. Despite grossly inadequate health insurance funding, most health care is financed out-of-pocket especially from the poor who live on less than a dollar a day [10]. A majority of health care funding either via health insurance or out of pocket are used for various kind of infectious diseases or infectious disease related illnesses.

Aside usurping the meager health care resources, infectious diseases are poverty promoting conditions for the individuals afflicted and for the general economy of the nation. The economic cost of these diseases is very profound as it reduces productivity owing to death and debilitating illness leading to reduced profitability and economic growth [1].

\section{Economic Burden of Malaria HIV/AIDS and Tuberculosis}

Malaria has caused untold hardship in Sub-Saharan Africa. Malaria is a mosquito-borne parasitic infectious disease caused by a protozoa organism called plasmodium. It is common in tropical areas of the world especially in sub Saharan Africa [11]. Plasmodium falciparum is the predominant specie responsible for severe infections in Sub Saharan Africa [11]. Malaria accounts for about 400 to 900 million yearly cases of febrile illness and about $75 \%$ of these are in children in Africa. Children are more predisposed because of rudimentary antiparasitic and clinical immunity [12]. Parents of infected children spend $25 \%$ of their house old income on treatment [3]. Malaria has been ranked as the second highest contributor to the Disability Adjusted Life Year (DALY). The DALY is an estimation of a disease's direct cause of mortality and morbidity [13]. There is decrease economic growth in country with severe malaria burden about $1.3 \%$ less than those without malaria [14]. Aside the snail speed economic growth, it was estimated that 25 of these countries lose $15 \%$ of their GDP to the disease [14].

HIV/AIDS also creates huge problems for the economies of many countries in Sub -Saharan Africa. It is caused by human immunodeficiency virus chiefly transmitted through exchange of body fluids, semen and blood. HIV infection usually progress to Acquired Immunodeficiency syndrome, a condition in humans characterized by progressive failure of the immune system leading to life-threatening opportunistic infections [15] 68\% of people that leave with HIV globally reside in the African continent [16]. Those infected are usually in the productive phase of their life. It is estimated that HIV/AIDS contributes to 72 million DALY and each AIDS death equals 34.6 D.A.L.Y lost on the average in 1999 [17]. These represent, in economic terms about $35.1 \%$ of GDP if each DALY is valued 3 times per capita income [3].

Tuberculosis on the other hand causes similar havoc to personal, family and national economies, having negative impact on working hours [18]. It is an infectious disease caused by mycobacterium tuberculosis. It is transmitted through droplets infection when persons with active infection sneeze and cough, releasing the infectious mycobacterium in the air [19]. Tuberculosis is principally a disease of poverty being very much linked to overcrowding and malnutrition [20]. It causes 20\% - 30\% loss of house hold earnings. About 8.4 million people are living with tuberculosis worldwide, causing about $30 \%$ average loss of productivity leading global economy loss of about I billion US dollars yearly [21] [22]. 


\section{Economic Burden of Epidemic Diseases}

Other epidemic diseases, though not present at all times have the potential to cause economic loss. They disrupt trade and commerce and put the economies of these countries in untold hard ship. Epidemic of emerging and reemerging diseases have the capacity to cause hardship and economic strain on nations affected. Diseases like cholera and Ebola cause severe strain on the poorly, underfunded health care resources of most countries in subSaharan Africa and by the time the epidemic is over thousand are dead especially those in the productive years of their life, and the economy is in tatters.

Cholera is one of the causes of diarrhea. It is an infection of the small intestine caused by vibrio cholera. It is characterize by profuse diarrhea and vomiting leading to massive loss of body fluids [23]. It is a disease that occurs commonly and repeatedly in sub Saharan Africa because majority of the population live in poor conditions and surroundings that favour the spread of this disease. Conditions like overcrowding, poor sanitation, improper sewage disposal, lack of portable water and lack of personal hygiene. In 2007, a total of 110,837 cases were reported to WHO from countries in Africa, with an estimated economic loss of 60 million dollars [24].

Ebola is a viral hemorrhagic fever of humans caused by the ebolaviruses [25]. A very virulent disease that kills $25 \%$ to $90 \%$ of those infected [26]. It is a highly contagious disease spread mainly by contact with body fluids [25]. The present Ebola crisis is a true example of what an epidemic and a re-emerging disease can do to a country's economy. Guinea, Seria Leone and Liberia are worst hit and have lost considerable manpower and income since the outbreak. World Bank estimates for 2014 shows that these three countries lost a significant amount of GDP growth which amounts to a total of US\$359 million. There are also recorded revenue shortfalls due to reduced economic activities, coupled with increased expenditures on health, security, and social protection. The financing gaps for the three core countries, summed up to over US\$290 million. If the epidemic continues there will be even greater financing gaps by the end of 2015 [27].

\section{Control and Prevention Strategies}

It will not be difficult to deduce at this juncture that preventing and controlling infectious disease will help in improving the lives of people and the economies of countries in sub Saharan Africa. Investing in measures to control and prevent this disease will indeed be good business for countries in sub-Saharan Africa. One can't help but imagine what it will be like if the African continent was not plagued with these diseases, Africa would have grown to realize her full potential taking her rightful place as a world power.

\section{Scaling up Already Existing Prevention and Control Program}

One of the sure ways to go in preventing and controlling infectious diseases is to scale up existing prevention programs. Investment in the scale up and upgrade of the present prevention and control programs will certainly be good business. It is very evident that the various control programs are yielding positive results. Malaria burden is gradually decreasing in most parts of sub Saharan Africa [28]. Progress was noted few years after the WHO three-prong approach was widely deployed in malaria endemic areas in Africa with increasing amount of coverage achieved [29]. In the same vein the control programs for HIV and TB have made progress in controlling these diseases [30]. Africa has not yet achieved the millennium developmental goals (MDG) but lessons to be learnt from these control programs is that if Africa keeps doing the right things she will win the fight against infectious diseases. Thus, it is apt to keep investing in already existing control programs by way of monitoring, evaluating and scaling up these programs.

\section{Active Infectious Disease Surveillance System}

Lack of infectious disease surveillance system is the bane of health care and public health in sub Saharan Africa. There is dearth of surveillance system in Africa [31]. This is the main reason why epidemic-prone infectious disease like cholera, Ebola and others are ravaging Africa at will. A good surveillance system in place for a particular infectious disease can be utilized for any emerging epidemic-prone infectious disease. A typical example is the Ebola epidemic in Nigeria. Nigeria was largely successful owing to the fact it called up its own polio surveillance response structure and manpower and established an Ebola response unit. From the polio response team, 40 of the Nigerian doctors trained in epidemiology were reassigned. This gave Nigeria a head start and advantage to eradicate Ebola in record time against all odds [32]. Investing in establishing an active integrated 
infectious disease surveillance system will be a positive investment to undertake to save people from preventable diseases and protecting the country's economy.

\section{Research in Infectious Diseases}

Research is another vital area in infectious disease that is lacking in sub Saharan Africa [31]. This area is very important in disease control. Research furnishes information concerning the epidemiology, pathogenesis, genetic makeup and other areas of the disease necessary to eliminate or control it. A typical example is what is happening with malaria control. Commendable progress is made in the control of malaria, but there is a huge challenge of drug resistance and genetic mutation that can be a cog in the wheel of progress made so far. Therefore it is imperative to invest in research in infectious disease so that we can be steps ahead of these pathogens and halt them in their stride.

\section{Man Power Training}

There is scarcity of trained infectious disease personnel in sub Saharan Africa [31]. Investing in training and capacity building is very necessary to help the fight against infectious disease. Most African countries have very few undergraduate, post graduate medical schools, and public health schools that can train epidemiologist, microbiologist, community disease surveillance officers etc. Medical doctors, nurses and other health workers should be encouraged to specialize in various areas of infectious disease. The Centre for Disease Control CDC organized field epidemiology training program (FETP) is very laudable program organized in some countries in Africa [25]. It trains field epidemiologists, arming them with necessary skills to collect, analyze and interpret data ensuring more rapid and effective response to health threat pose by infectious diseases [33]. More investment should be made in this area as it will be profitable in the long run.

\section{Political Leadership}

Lack of political will is another worrying problem in sub Saharan. There is no political leadership in the fight against infectious diseases. Health budgets are grossly inadequate and the little allocated to health are usually not utilized as corruption take the better part of the budget. Political leaders must begin to listen to the health sector. The present epidemic of Ebola will hopefully change the nonchalant attitude of politicians. Political leaders should invest much more in the health sector especially in the area of infectious disease control and prevention. Government of the day must provide the basic amenities like adequate shelter, access to clean drinking water, etc. These investments will surely be profitable at the end of the day.

\section{Conclusion}

Though poverty in Africa is a multifaceted problem, infectious diseases contribute a significant fraction in the region. Poverty and infectious diseases are so interwoven in dynamic terms that positive improvement of one will alleviate the negative impact of the order. Control and prevention of infectious disease have palpable benefits on health outcome of the population with subsequent increase in labour productivity, educational attainment and positive capital investment [34]. The call to invest more in the control and prevention of infectious diseases as a means to curb poverty is a noble cause that should be embraced by the whole continent of Africa and the world at large. This is important because if one country is still grappling with the menace of infectious diseases the whole of Africa and the world is still at risk.

\section{References}

[1] Fonkwo, P.N. (2008) Pricing Infectious Disease: The Economic and Health Implications of Infectious Diseases. EMBO Reports, 9, S13-S17. http://dx.doi.org/10.1038/embor.2008.110

[2] Young, F., Critchley, J., Johnstone, C. and Unwin, N. (2010) Globalization and the Dual Disease Burden in Sub-Saharan Africa. Diabetes Voice, 55, 30-32.

[3] Lopez, A.D., Mathers, C.D., Ezzati, M., Jamison, D.T. and Murray, C.J. (2006) Global and Regional Burden of Disease and Risk Factors, 2001: Systematic Analysis of Population Health Data. The Lancet, 367, 1747-1757. http://dx.doi.org/10.1016/S0140-6736(06)68770-9 
[4] Mathers, C., Fat, D.M. and Boerma, J.T. (2008) The Global Burden of Disease: 2004 Update. World Health Organization, Geneva.

[5] WHO Global Disease Burden (2010) Executive Summary—The Lancet. http://www.who.int/pmnch/media/news/2012/who_burdenofdisease/en

[6] World Health Organisation Report (2010) Equity, Social Determinants and Public Health Programmes. http://whqlibdoc.who.int/publications/2010/9789241563970_eng.pdf

[7] Patz, J.A., Githeko, A.K., Mccarty, J.P., Hussein, S., Confalonieri, U. and De Wet, N. (2003) Climate Change and Infectious Diseases. In: Mcmichael, A.J., Campbell-Lendrum, D.H., Corvalán, C.F., Ebi, K.L., Githeko, A.K., Scheraga, J.D. and Woodward, A., Eds., Climate Change and Human Health. Risks and Responses, World Health Organization, Geneva, 103-132.

[8] Jha, P., Chaloupka, F.J., Moore, J., Gajalakshmi, V., Gupta, P.C., Peck, R. and Claeson, M. (2006) Disease Control Priorities in Developing Countries. World Bank Publications, Washington DC.

[9] Plewes, T.J. and Kinsella, K. (2012) The Continuing Epidemiological Transition in Sub-Saharan Africa: A Workshop Summary. National Academies Press, Washington DC

[10] Carapinha, J.L., Ross-Degnan, D., Desta, T.A. and Wagner, K.A. (2010) Health Insurance Systems in Five Sub-Saharan African Countries: Medicine Benefits and Data for Decision Making. Health Policy, 99, 193-202.

[11] WHO (2014) Malaria Facts Sheets. http://www.who.int/mediacentre/factsheets/fs094/en/

[12] Bull, P.C. and Marsh, K. (2002) The Role of Antibodies to Plasmodium Falciparum-Infected-Erythrocyte Surface Antigens in Naturally Acquired Immunity to Malaria. Trends in Microbiology, 10, 55-58. http://dx.doi.org/10.1016/S0966-842X(01)02278-8

[13] Snow, R.W., Newton, C.R., Craig, M.H. and Steketee, R.W. (2003) The Public Health Burden of Plasmodium Falciparum Malaria in Africa. Disease Control Priorities Project. Working Paper No. 11, Fogarty International Centre, National Institute of Health, Bethesda.

[14] Gallup, J.L. and Sachs, J.D. (2000) The Economic Burden of Malaria. Center for International Development at Harvard University, Cambridge, MA. www.cid.harvard.edu

[15] Weiss, R.A. (1993) How Does HIV Cause AIDS? Science, 260, 1273-1279. http://dx.doi.org/10.1126/science.8493571

[16] WHO (2011) Global Health Sector Strategy on HIV/AIDS 2011-2015. World Health Organisation Report. http://whqlibdoc.who.int/publications/2011/9789241501651_eng.pdf

[17] WHO (2003) Macro Economics and Health: The Way Forward in the African Region. World Health Organization, Geneva.

[18] WHO (2008) The Burden of Tuberculosis: Economic Burden. World Health Organization, Geneva. www.who.int

[19] Konstantinos, A. (2010) Testing for Tuberculosis. Australian Prescriber, 33, 12-18.

[20] Lawn, S.D. and Zumla, A.L (2011) Tuberculosis. The Lancet, 378, 57-72. http://dx.doi.org/10.1016/S0140-6736(10)62173-3

[21] Kim, J.Y., Shakow, A., Castro, A., Vande, C. and Farmer, P. (2008) Tuberculosis Control. World Health Organization, Geneva. www.who.int

[22] World Health Organization, Global Tuberculosis Programme (1997) Treatment of Tuberculosis: Guidelines for National Programmes. 2nd Edition, World Health Organization, Geneva. Publication WHO/GTB/96.210.

[23] Baron, S. and Finkelstein, R.A. (1996) Cholera, Vibrio cholerae O1 and O139, and Other Pathogenic Vibrios.

[24] Kirigia, J.M., Sambo, L.G., Yokouide, A., Soumbey-Alley, E., Muthuri, L.K. and Kirigia, D.G. (2009) Economic Burden of Cholera in the WHO African Region. BMC International Health and Human Rights, 9, 8. http://dx.doi.org/10.1186/1472-698X-9-8

[25] Patil, M.S., Patil, M.J., Patil, N.S., Suryawanshi, H.P. and Pawar, S.P. (2015) Review on Ebola Virus Disease.

[26] WHO (2014) Ebola Facts Sheets. http://www.who.int/mediacentre/factsheets/fs103/en/

[27] World Bank (2014) The Economic Impact of the 2014 Ebola Epidemic: Short- and Medium-Term Estimates for West Africa. World Bank, Washington DC.

[28] WHO (2003) Africa Malaria Report 2003. World Health Organization/UNICEF. WHO/CDC/MAL/2003.

[29] WHO (2000) The African Summit on Roll Back Malaria, Abuja, Nigeria. WHO/CDS/RBM, Geneva.

[30] UNAIDS (2010) UNAIDS Report on the Global AIDS Epidemic. United Nations Programme on HIV/AIDS, Geneva.

[31] Lockwood, D.N. (2002) Emerging Infectious Diseases from the Global to the Local Perspective: A Summary of a Workshop of the Forum on Emerging Infections. Davis, J.R. and Lederberg, J., Eds., Institute of Medicine, National Academy Press, Washington DC, 118 p. 
[32] The Guardian News Paper (2014).

http://www.theguardian.com/global-development/poverty-matters/2014/oct/07/nigeria-ebola-experience-teach-world

[33] CDC (2015) Field Epidemiology Training Program. http://www.cdc.gov/globalhealth/healthprotection/fetp/

[34] Alsan, M.M., Westerhaus, M., Herce, M., Nakashima, K. and Farmer, P.E. (2011) Poverty, Global Health, and Infectious Disease: Lessons from Haiti and Rwanda. Infectious Disease Clinics of North America, 25, 611-622. http://dx.doi.org/10.1016/j.idc.2011.05.004

\section{Abbreviations}

GDP: Gross Domestic Product

DALY: Disability Adjusted Life Years

HIV: Human Immunodeficiency Virus

AIDS: Acquired Immunodeficiency Syndrome

CDC: Centre for Disease Control

WHO: World Health Organization

FETP: Field Epidemiology Training Program

TB: Tuberculosis

MDG: Millennium Developmental Goals 